\title{
Distribuição espacial de cobre, zinco e níquel em um Latossolo após quinze anos da aplicação de lodo de esgoto
}

\author{
Carlos Antonio Centurion Maciel ('); Otávio Antonio de Camargo (²); Sidney Rosa Vieira (2); Marcio \\ Koiti Chiba $\left({ }^{2 *}\right)$
}

(') Faculdade de Agronomia Manoel Carlos Gonçalves (UniPinhal), Centro Regional Universitário de Espírito Santo do Pinhal, Av. Hélio Vergueiro Leite, 1, 13990-000 Espírito Santo do Pinhal (SP), Brasil.

(2) Instituto Agronômico, Centro de Pesquisa e Desenvolvimento de Solos e Recursos Ambientais, Av. Barão de Itapura, 1481, 13020-902 Campinas (SP), Brasil.

(*) Autor correspondente: mkchiba@iac.sp.gov.br

Recebido: 26/jun./2012; Aceito: 16/nov./2012

\section{Resumo}

A utilização agrícola do lodo de esgoto como fonte de nutrientes para as plantas é uma das alternativas mais viáveis de reciclar este material sem comprometer a qualidade do meio ambiente. Este trabalho foi realizado visando quantificar e mapear os teores de cobre, zinco e níquel em um solo após quinze anos da aplicação de lodo de esgoto (LE). De 1983 a 1987, a área experimental foi utilizada em um ensaio com doses de 0, 20, 40, 60 e $80 \mathrm{Mg} \mathrm{ha}^{-1}$ de lodo de esgoto e de nitrogênio (0, 50, 100 e $150 \mathrm{~kg} \mathrm{ha}^{-1}$ ) em cultivo de milho. Com o término deste experimento, o solo permaneceu sob pousio com gramínea (Brachiaria decumbens Stapf) e, em 2002, foram coletadas novas amostras de terra, nas camadas de 0-20 cm e de 20-40 cm de profundidade e da parte aérea das plantas de maneira georreferenciada. As amostragens foram realizadas a cada $3 \mathrm{~m}$ sobre três transeções distantes 15 m uma da outra e locadas em ângulo de $45^{\circ}$ em relação aos limites da área experimental, totalizando 50 pontos amostrais. Os dados foram analisados inicialmente em função dos momentos estatísticos descritivos e a variabilidade espacial dos atributos do solo e da planta foi determinada por análise geoestatística utilizando semivariogramas que permitiram também a obtenção de mapas interpolados por krigagem desses parâmetros. Os atributos do solo pH, MOS e CTC não estão correlacionados com os teores de Cu, Zn e Ni no solo e nas plantas. Tanto o DTPA quanto o Mehlich-3 foram eficientes na predição da disponibilidade de Zn no solo e na planta. Após 15 anos da aplicação de biossólido, os teores de Cu, Zn e Ni na camada de 0-20 cm de profundidade e determinados tanto com DTPA quanto Mehlich-3, estavam com estrutura de dependência espacial classificada como forte e/ou moderada. $\mathrm{O}$ grau de dependência espacial dos teores de Cu, Zn e Ni, nas plantas, foi diferente do verificado para esses elementos no solo.

Palavras-chave: krigagem, metais pesados, geoestatística, poluição do solo.

\section{Soil spatial distribution of copper, zinc and nickel fifteen years after last application of sewage sludge}

\begin{abstract}
Application of sewage sludge (SS) in agricultural land may be considered a rationale way to recycle this residue as source of plant nutrients and reduce its environmental impact. This work aimed to describe the spatial distribution of soil content of copper, zinc and nickel in a Typic Clayed Hapludox fifteen years after the last application of sewage sludge on it. From 1983 to 1987 the experimental plot was used in an assay with SS application at rates of 0, 20, 40,60 and 80 t ha ${ }^{-1}$ and mineral

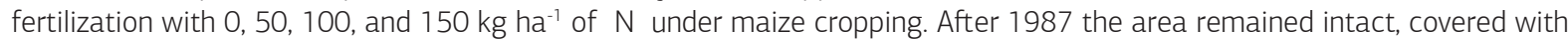
signal grass (Brachiaria decumbens Stapf) vegetation, up to 2002 when soil and plant sampling were accomplished according to a spatial grid. Soil samples from 0-20 cm and at 20-40 cm depths, and aerial part of the grass were taken for chemical analysis. Soil and plant sampling were performed each $3 \mathrm{~m}$ in three parallel transects $15 \mathrm{~m}$ apart each other with an inclination of $45^{\circ}$ in relation to the original baseline of the experimental area, completing fifty points of sampling. In order to assess the spatial variability of soil attributes and plant, geostatistics tools were used to determine the semivariograms and to draft the maps of isolines, as well as descriptive statistics for calculation of some parameters. Soil pH, soil organic matter and cation exchange capacity were not correlated with $\mathrm{Cu}, \mathrm{Zn}$ and Ni for soil and plant. Both DTPA and Mehlich-3 were efficient to predict zinc availability. After 15 years of biosolid application Cu, Zn and Ni content at 0-20 cm depth, evaluated by DTPA and Mehlich-3, presented strong to moderate spatial dependency structure. Although, the degree of spatial dependency for $\mathrm{Cu}, \mathrm{Zn}$ and $\mathrm{Ni}$ in plant tissues was different than the observed in the soil.
\end{abstract}

Key words: kriging, heavy metals, geostatistics, soil pollution. 


\section{INTRODUÇÃO}

A disposição de lodo de esgoto (LE) em áreas agrícolas constitui uma alternativa viável ao seu descarte em aterros sanitários tendo em vista que a capacidade destes últimos em receber resíduos é limitada, além de não trazer benefícios na produção de diversas culturas em função do aporte de elementos químicos que são nutrientes de plantas (Bettiol e Carvalho, 1982; Berton et al., 1989; Martins et al., 2003). A matéria orgânica adicionada via LE, pela sua capacidade de melhorar algumas características físicas do solo (De MARIA et al., 2010), aliada à presença de nutrientes como nitrogênio, fósforo, cálcio, enxofre, zinco, cobre e manganês, torna atrativa a disposição deste material nos solos cultivados (GARDINER et al., 1995).

Apesar dos aspectos positivos da aplicaçáo do LE nos solos agrícolas, problemas como a presença de patógenos e de metais pesados requerem o monitoramento constante do solo visando preservar sua qualidade. Alguns estudos têm indicado que os patógenos presentes no lodo de esgoto têm reduzida persistência no meio ambiente (BERTON, 2000) e podem ser eliminados com algumas medidas de pós-processamento do LE ainda nas estaçôes de tratamento de esgoto (ETE).

Os metais pesados podem permanecer no solo por longos períodos, especialmente em solos tropicais ricos em óxidos de ferro e de alumínio. Apesar da maioria dos metais pesados presentes no LE também se constituir de nutriente de planta, as quantidades aportadas são, geralmente, maiores que as necessidades da maioria das espécies cultivadas, o que pode ocasionar problemas ambientais (Walter et al., 2002; Trannin et al., 2008).

Em estudo realizado por dois anos consecutivos, GALDos et al. (2004) verificaram que aplicaçôes de $10 \mathrm{e}$ de $20 \mathrm{Mg} \mathrm{ha}^{-1} \mathrm{LE}$ em um Latossolo Vermelho argiloso resultaram no aumento da concentraçáo de $\mathrm{Cu}, \mathrm{Zn}$ e Ni em plantas de milho. Contudo, em outros estudos realizados com doses elevadas de LE, atingindo até $300 \mathrm{Mg} \mathrm{ha}^{-1}$, LogAn et al. (1997) verificaram que a absorção de metais pesados pelas plantas náo ocorre de forma linear, provavelmente em virtude das interaçôes entre esses metais e componentes do solo como $\mathrm{pH}$, matéria orgânica e CTC (Shuman, 1991; Camargo et al., 2001).

Borges e Coutinho (2004), estudando o fracionamento de metais em Latossolo Vermelho argiloso tratado com $\mathrm{LE}$, verificaram que as quantidades de $\mathrm{Zn}$, $\mathrm{Cu}$ e Ni absorvidas por plantas de milho correlacionaram-se significativamente $(\mathrm{p}<0,05)$ com as quantidades extraídas com solução de DTPA pH 7,3 e por Mehlich-3. Nos modelos matemáticos ajustados aos teores extraídos pelas duas soluçôes houve participação significativa das frações trocável e orgânica e, apesar disso, em termos quantitativos a maior parte desses metais estava associada às formas mais estáveis e ligadas a óxidos de $\mathrm{Fe}$ e $\mathrm{Al}$ e fração residual.
Em estudo anterior realizado no mesmo experimento que o deste trabalho, tanto o DPTA quanto o Mehlich-3 foram eficazes em predizer a disponibilidade de $\mathrm{Cu}$ e $\mathrm{Zn}$ do solo para plantas de milho (Martins et al., 2003). Segundo esses autores, com o aumento do $\mathrm{pH}$ do solo a capacidade dos extratores diminui, evidenciando a relaçáo entre a reação do solo e a eficiência deles em predizer a disponibilidade desses metais.

De acordo com Bidwell e Dowdy (1987), os maiores teores disponíveis de metais pesados adicionados via LE seriam determinados no período imediatamente subsequente à sua aplicaçáo no solo; com o tempo, ocorreria diminuição da taxa de composiçáo do material orgânico reduzindo a disponibilidade dos metais pesados. Estes ao serem absorvidos pelas plantas e, posteriormente, ciclados no sistema solo-planta seriam devolvidos ao solo. Nogueira et al. (2008) estudaram o efeito cumulativo de nove aplicaçóes de doses de LE na disponibilidade de metais pesados em um Latossolo argiloso cultivado com milho e apenas verificaram aumentos significativos relacionados com os teores foliares de $\mathrm{Zn}$.

Em uma área em que toda biomassa produzida não é removida, espera-se que eventuais manchas de solo com maior concentração de alguns elementos químicos tendem a desaparecer com o tempo, náo sendo possível encontrar uma função de dependência espacial que possa ser utilizada para seu mapeamento. São escassas as informaçóes de longo prazo acerca do impacto do uso de LE em solos tropicais, onde óxidos de ferro e matéria orgânica desempenham importante papel na dinâmica dos metais pesados no solo (Silveira et al., 2003), assim como sobre sua variabilidade espacial e disponibilidade para as plantas. Neste contexto, este trabalho teve como objetivo estudar a variabilidade espacial dos teores de $\mathrm{Cu}, \mathrm{Zn}$ e Ni disponíveis, em solo argiloso que recebeu LE por quatro anos consecutivos e ficou sob pousio por quinze anos após cessar a aplicação do resíduo, utilizando dois extratores químicos.

\section{MATERIAL E MÉTODOS}

Em vista da dificuldade em instalar e acompanhar um experimento de longa duraçáo para o estudo do efeito residual e da biodisponibilidade de metais provenientes da aplicação de lodo de esgoto (LE), utilizou-se uma área previamente tratada com LE entre os anos de 1983 a 1987, sob Latossolo Vermelho distrófico típico, textura argilosa, a qual por estar em uma estaçáo experimental tinha-se certeza de que nunca teria havido alteração antrópica. Sua camada de $0-20 \mathrm{~cm}$ de profundidade tinha as seguintes características químicas: $\mathrm{pH}\left(\mathrm{CaCl}_{2}\right)=3,9 ; \mathrm{MO}=48 \mathrm{~g} \mathrm{~kg}^{-1}$; $\mathrm{P}=5 \mathrm{mg} \mathrm{dm}^{-3} ; \mathrm{K}, \mathrm{Ca}, \mathrm{Mg}, \mathrm{H}+\mathrm{Al} \mathrm{e} \mathrm{CTC}=1,6 ; 3 ; 1 ; 97 \mathrm{e}$ $103 \mathrm{mmol}_{\mathrm{c}} \mathrm{dm}^{-3}$ respectivamente. A análise granulométrica do solo indicou que havia: $75 \mathrm{~g} \mathrm{~kg}^{-1}$ de areia grossa; 
$200 \mathrm{~g} \mathrm{~kg}^{-1}$ de areia fina; $145 \mathrm{~g} \mathrm{~kg}^{-1}$ de silte e $580 \mathrm{~g} \mathrm{~kg}^{-1}$ de argila, conforme método descrito por CAMARGO et al. (1986). Nesta área havia sido instalado um experimento com 11 tratamentos (1- Controle; 2- LE, aplicação única de $20 \mathrm{Mg} \mathrm{ha}^{-1}$ em 1983; 3- LE, $40 \mathrm{Mg} \mathrm{ha}^{-1}$ em duas aplicaçóes fracionadas de $20 \mathrm{Mg} \mathrm{ha}^{-1} \mathrm{em} 1983$ e em 1984; 4- LE, aplicação única de $40 \mathrm{Mg} \mathrm{ha}^{-1} \mathrm{em} \mathrm{1983;} \mathrm{5-} \mathrm{LE,}$ $60 \mathrm{Mg} \mathrm{ha}^{-1} \mathrm{em}$ três aplicaçóes fracionadas de $20 \mathrm{Mg} \mathrm{ha}^{-1}$ em 1983, 1984 e 1985; 6- LE, aplicação única de $60 \mathrm{Mg} \mathrm{ha}^{-1} \mathrm{em} \mathrm{1983;} \mathrm{7-} \mathrm{LE,} 80 \mathrm{Mg} \mathrm{ha}^{-1}$ em quatro aplicaçóes fracionadas de $20 \mathrm{Mg} \mathrm{ha}^{-1} \mathrm{em} \mathrm{1983,} \mathrm{1984,} 1985$ e 1986; 8- LE, aplicação única de $80 \mathrm{Mg} \mathrm{ha}^{-1} \mathrm{em} \mathrm{1983;}$ 9- Uréia, $50 \mathrm{~kg} \mathrm{ha}^{-1}$ ano $^{-1} ; 10$ - Uréia, $100 \mathrm{~kg} \mathrm{ha}^{-1}$ ano- $^{-1}$; 11 - Uréia, $150 \mathrm{~kg} \mathrm{ha}^{-1}$ ano $^{-1}$ e quatro repetiçôes em blocos casualizados, cultivando milho em parcelas com $6 \times 7 \mathrm{~m}$ (Jorge et al., 1991; Martins et al., 2003).

O LE aplicado era proveniente da ETE-SABESP de Vila Leopoldina, São Paulo, consistindo de um lodo digerido anaerobicamente, não tratado com $\mathrm{CaO}$ nem com cloreto férrico e cujas características químicas são apresentadas na tabela 1 .

Em outubro de 1983, o LE foi aplicado manualmente no solo e incorporado em uma camada de $15 \mathrm{~cm}$ de profundidade e reaplicado, conforme o tratamento em 1984, 1985 e 1986. Durante este período, a área experimental foi cultivada com milho, recebendo anualmente $100 \mathrm{~kg} \mathrm{ha}^{-1}$ de superfosfato simples e $60 \mathrm{~kg} \mathrm{ha}^{-1}$ de cloreto de potássio. Em 1987, após o quarto plantio sucessivo de milho (MarTins et al., 2003) o experimento foi encerrado, ficando a área experimental ocupada por capim braquiária (Brachiaria decumbens Stapf) de 1987 a 1999, e durante este período o capim era apenas roçado e deixado sobre o solo.

Em 1999, retornou-se a esta área e foram locados três transetos distanciados de $15 \mathrm{~m}$ entre si e locados em ângulo de $45^{\circ}$ à linha de base que formava o retângulo que delimitava o ensaio instalado em 1983 (Figura 1). Sobre esses transetos foram coletadas 50 amostras de solo a cada $3 \mathrm{~m}$, nas camadas de $0-20$ e de $20-40 \mathrm{~cm}$ de profundidade com trado holandês. Essas amostras foram homogeneizadas, peneiradas em peneira de malha de $2 \mathrm{~mm}$ de abertura, secas e analisadas segundo RAIJ et al. (1987). Alternativamente ao método padrão que usou solução complexante de DTPA pH 7,3 (LindsAy e Norvell, 1978), os teores de $\mathrm{Cu}, \mathrm{Zn}$ e Ni também foram quantificados em extração com solução Mehlich-3 (Mehlich, 1984).

Amostras de folhas de capim braquiária também foram coletadas nos mesmos pontos de amostragem de solo, cortando a parte aérea das plantas na altura do solo. O material vegetal foi lavado, seco em estufa por 72 horas a $65-70{ }^{\circ} \mathrm{C}$, moído em moinho de aço inoxidável e analisado para os teores de $\mathrm{Cu}, \mathrm{Zn}$ e $\mathrm{Ni}$ após digestão nítrico-perclórica por espectrofotometria de absorção atômica, conforme Malavolta et al. (1997).
Tabela 1. Características químicas ${ }^{(1)}$ do lodo de esgoto utilizado entre 1983 a 1986 em Latossolo argiloso

\begin{tabular}{lrrrr}
\hline Atributo & \\
$\mathrm{C}(2)$ & 1983 & $\mathbf{1 9 8 4}$ & $\mathbf{1 9 8 5}$ & $\mathbf{1 9 8 6}$ \\
$\mathrm{C}\left(\mathrm{g} \mathrm{kg}^{-1}\right)$ & 217 & 265 & 261 & 286 \\
$\mathrm{Ca}\left(\mathrm{g} \mathrm{kg}^{-1}\right)$ & 14 & 16 & 16 & 9 \\
$\mathrm{P}\left(\mathrm{g} \mathrm{kg}^{-1}\right)$ & 24 & 15 & 20 & 21 \\
$\mathrm{Cu}\left(\mathrm{mg} \mathrm{kg}^{-1}\right)$ & 8 & 2 & 2 & 2 \\
$\mathrm{Zn}\left(\mathrm{mg} \mathrm{kg}^{-1}\right)$ & 791 & 975 & 1.148 & 989 \\
$\mathrm{Ni}\left(\mathrm{mg} \mathrm{kg}^{-1}\right)$ & 1.888 & 2.904 & 3.326 & 4.035 \\
\hline Umidade $\left(\mathrm{g} \mathrm{kg}^{-1}\right)$ & 342 & 410 & 459 & 1.240 \\
\hline
\end{tabular}

(') Em base no material seco; (2) Dados compilados de Jorge et al., (1991); Martins et al., (2003).

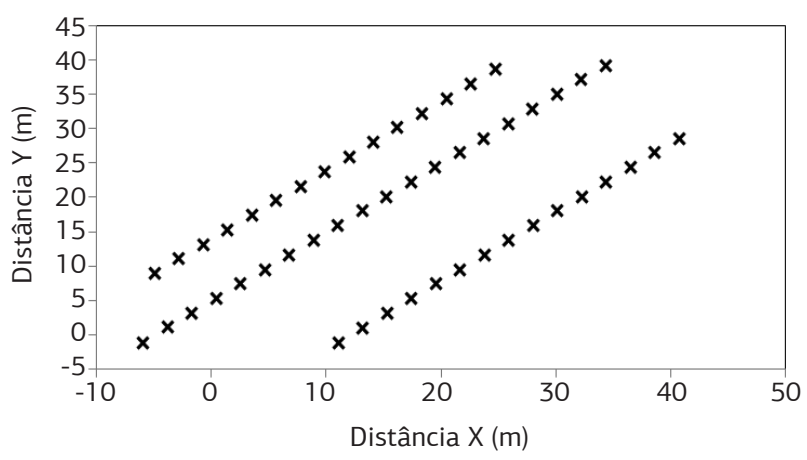

Figura 1. Distribuição espacial dos pontos amostrais e das transeções em uma área que recebeu lodo de esgoto entre 1983 e 1986 e foi amostrada para os teores disponíveis de $\mathrm{Cu}, \mathrm{Zn}$ e $\mathrm{Ni}$ em 1999, nas camadas de $0-20$ e $20-40 \mathrm{~cm}$ de profundidade.

Os dados de solo e planta foram analisados inicialmente para as características estatísticas descritivas e ajuste dos dados à distribuiçấo do tipo normal e, posteriormente, utilizada em cálculos geoestatísticos para verificação da existência de dependência espacial e estimativa do semivariograma, conforme método descrito por VIEIRA (2000). A dependência espacial foi avaliada conforme critério estabelecido por CAmbardella et al. (1994) que define dependência espacial forte para semivariogramas com efeito pepita menor ou igual a $25 \%$ do patamar, moderada entre 25 e $75 \%$ e fraca quando for maior que $75 \%$. Para os dados com estrutura de dependência espacial definida pelo semivariograma, foi realizada interpolação por krigagem com a finalidade de estimar valores para a variável em questão, em locais náo amostrados a partir dos valores dos pontos vizinhos com mínimo de erro.

\section{RESULTADOS}

As quantidades de $\mathrm{Cu}, \mathrm{Zn}$ e $\mathrm{Ni}$ aportadas no solo em 1983; 1984; 1985 e 1986, de acordo com os tratamentos e as variaçōes sazonais na concentração desses elementos no lodo de esgoto, são apresentadas na tabela 2 . 
Quinze anos após cessar a aplicação de lodo de esgoto no solo, a variação nos teores disponíveis de $\mathrm{Cu}$, Zn e Ni foi elevada, com valores de CV acima de 30\% para todos os elementos e as profundidades analisadas, considerando os diferentes extratores utilizados: DTPA pH 7,3 (Tabela 3); solução de Mehlich-3 (Tabela 4). Entre os extratores, a maior variação foi verificada usando o Mehlich-3 (Tabela 4), com valores de CV de até 266,6\% como verificado para o $\mathrm{Zn}$ na camada de $20-40 \mathrm{~cm}$ de profundidade. Apenas para o cobre, na camada de 0-20 cm e extraído com Mehlich-3, foi verificada uma distribuição de dados do tipo normal, pelo teste de Kolmogorov-Smirnov a 5\% de probabilidade (Tabela 4). Tanto o DTPA quanto a solução Mehlich-3 têm sido descritos como eficientes na predição da biodisponibilidade de $\mathrm{Cu}$ e $\mathrm{Zn}$ para as plantas (Oliveira e Mattiazzo, 2001; Anjos e Mattiazzo, 2000, Pires e Mattiazzo, 2003). O mesmo, entretanto, não pode ser verificado para o níquel (Anjos e Mattiazzo, 2000; 2001; Oliveira e Mattiazzo, 2001).

Tabela 2. Doses de lodo de esgoto aplicadas por tratamento, em diferentes anos, e teores de cobre, zinco e níquel aportados no solo na área experimental

\begin{tabular}{|c|c|c|c|c|c|}
\hline Tratamento & 1983 & 1984 & 1985 & 1986 & Acumulado \\
\hline $\mathrm{T} 1$ & & & Controle & & \\
\hline T2 & $20 \mathrm{Mg} \mathrm{ha}^{-1}$ & & & & $\begin{array}{r}\mathrm{Cu}=15,82 \mathrm{~kg} \mathrm{ha}^{-1} \\
\mathrm{Zn}=37,76 \mathrm{~kg} \mathrm{ha}^{-1} \\
\mathrm{Ni}=6,84 \mathrm{~kg} \mathrm{ha}^{-1}\end{array}$ \\
\hline T3 & $20 \mathrm{Mg} \mathrm{ha}^{-1}$ & $20 \mathrm{Mg} \mathrm{ha}^{-1}$ & & & $\begin{array}{l}\mathrm{Cu}=35,32 \mathrm{~kg} \mathrm{ha}^{-1} \\
\mathrm{Zn}=95,86 \mathrm{~kg} \mathrm{ha}^{-1} \\
\mathrm{Ni}=15,04 \mathrm{~kg} \mathrm{ha}^{-1}\end{array}$ \\
\hline T4 & $40 \mathrm{Mg} \mathrm{ha}^{-1}$ & & & & $\begin{array}{l}\mathrm{Cu}=31,64 \mathrm{~kg} \mathrm{ha}^{-1} \\
\mathrm{Zn}=75,52 \mathrm{~kg} \mathrm{ha}^{-1} \\
\mathrm{Ni}=13,68 \mathrm{~kg} \mathrm{ha}^{-1}\end{array}$ \\
\hline T5 & $20 \mathrm{Mg} \mathrm{ha}^{-1}$ & $20 \mathrm{Mg} \mathrm{ha}^{-1}$ & $20 \mathrm{Mg} \mathrm{ha}^{-1}$ & & $\begin{array}{r}\mathrm{Cu}=58,28 \mathrm{~kg} \mathrm{ha}^{-1} \\
\mathrm{Zn}=162,38 \mathrm{~kg} \mathrm{ha}^{-1} \\
\mathrm{Ni}=22,88 \mathrm{~kg} \mathrm{ha}^{-1}\end{array}$ \\
\hline T6 & $60 \mathrm{Mg} \mathrm{ha}^{-1}$ & & & & $\begin{array}{r}\mathrm{Cu}=47,46 \mathrm{~kg} \mathrm{ha}^{-1} \\
\mathrm{Zn}=113,28 \mathrm{~kg} \mathrm{ha}^{-1} \\
\mathrm{Ni}=20,52 \mathrm{~kg} \mathrm{ha}^{-1}\end{array}$ \\
\hline T7 & $20 \mathrm{Mg} \mathrm{ha}^{-1}$ & $20 \mathrm{Mg} \mathrm{ha}^{-1}$ & $20 \mathrm{Mg} \mathrm{ha}^{-1}$ & $20 \mathrm{Mg} \mathrm{ha}^{-1}$ & $\begin{array}{r}\mathrm{Cu}=78,08 \mathrm{~kg} \mathrm{ha}^{-1} \\
\mathrm{Zn}=193,98 \mathrm{~kg} \mathrm{ha}^{-1} \\
\mathrm{Ni}=47,68 \mathrm{~kg} \mathrm{ha}^{-1}\end{array}$ \\
\hline T8 & $80 \mathrm{Mg} \mathrm{ha}^{-1}$ & & & & $\begin{array}{r}\mathrm{Cu}=63,28 \mathrm{~kg} \mathrm{ha}^{-1} \\
\mathrm{Zn}=151,04 \mathrm{~kg} \mathrm{ha}^{-1} \\
\mathrm{Ni}=27,36 \mathrm{~kg} \mathrm{ha}^{-1}\end{array}$ \\
\hline
\end{tabular}

Obs.: Os tratamentos T9-T11, consistiram da aplicação de ureia como fonte de N, sem aplicação de resíduo e náo estão sendo mostradas aqui.

Tabela 3. Análise estatística descritiva para os teores de Zn, Cu e Ni extraídos com DTPA pH 7,3, em duas profundidades, em solo que recebeu lodo de esgoto

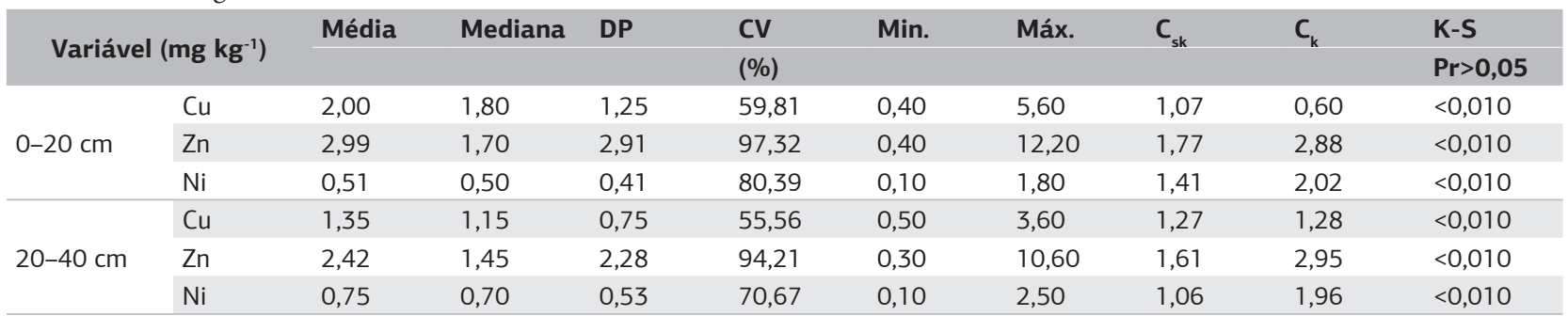

DP: desvio-padrāo; CV: coeficiente de variação; Mín.: valor mínimo; Máx.: valor máximo; $\mathrm{C}_{\mathrm{sk}}$ : coeficiente de assimetria; $\mathrm{C}_{\mathrm{k}}$ : coeficiente de curtose; K-S: teste de Kolmogorov-Sminov.

Tabela 4. Análise estatística descritiva para os teores de Zn, Cu e Ni extraídos com solução Mehlich-3 nas camadas de 0-20 e 20-40 cm de profundidade em solo que recebeu lodo de esgoto

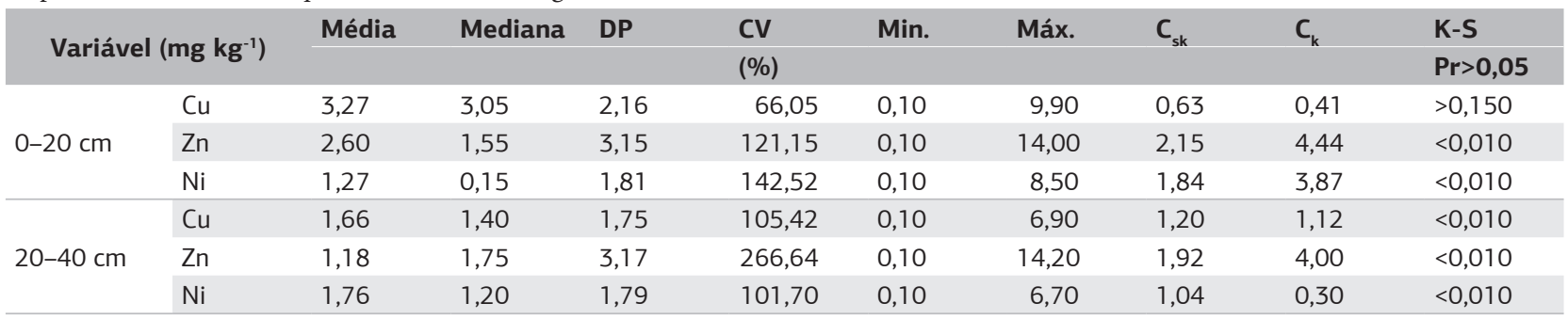

DP: desvio-padrão; CV: coeficiente de variaçẫo; Mín.: valor mínimo; Máx.: valor máximo; $\mathrm{C}_{\mathrm{sk}}$ : coeficiente de assimetria; $\mathrm{C}_{\mathrm{k}}$ : coeficiente de curtose; $\mathrm{K}-\mathrm{S}$ : teste de Kolmogorov-Sminov. 
Após a interrupção da aplicação de LE, toda a biomassa produzida foi apenas manejada por meio de cortes periódicos, sendo deixada sobre o solo e não havendo cultivo, não são esperadas alteraçóes significativas no $\mathrm{pH}, \mathrm{MOS}$ e CTC em profundidade, visto que tais atributos estão sendo descritos para a camada superficial de 0-20 cm (Tabela 5). Apenas no conteúdo de matéria orgânica do solo (MOS) houve distribuição de frequência do tipo normal (Tabela 5). Para os valores de $\mathrm{pH}$, MOS e CTC, a dispersão dos dados, medida pelo coeficiente de variação, esteve abaixo de $30 \%$, caracterizando baixa variabilidade. Comparando os valores desses atributos com os verificados antes do início do ensaio, verifica-se que o $\mathrm{pH}$ médio da área estudada passou de 3,9 para cerca de 4,2 , e os teores de matéria orgânica do solo e de CTC foram reduzidos de $48 \mathrm{~g} \mathrm{~kg}^{-1}$ para cerca de $28 \mathrm{~g} \mathrm{~kg}^{-1}$ e de 103 para $98 \mathrm{mmol}_{\mathrm{c}} \mathrm{dm}^{-3}$ respectivamente.

Os teores foliares de $\mathrm{Cu}, \mathrm{Zn}$ e $\mathrm{Ni}$ acompanharam a variabilidade verificada para a disponibilidade desses elementos no solo (Tabela 6), com coeficientes de variação de valores entre 45 e $80 \%$. Considerando a capacidade dos extratores em predizer as quantidades de $\mathrm{Cu}, \mathrm{Zn}$ e $\mathrm{Ni}$ absorvidas pelas plantas, verifica-se que para o zinco houve correlação significativa e positiva tanto usando o DTPA pH 7,3 (r=0,70; $\operatorname{Pr}<0,05)$ quanto o Mehlich-3 $(\mathrm{r}=0,63 ; \operatorname{Pr}<0,05)$ (Figura 2a).

Também foi observada correlaçấo significativa e negativa entre o teor de $\mathrm{Cu}$ na planta e o conteúdo de matéria orgânica do solo ( $\mathrm{r}=-0,312 ; \operatorname{Pr}=0,027)$ (Figura 3d). Adicionalmente, parece existir uma relação positiva entre $\mathrm{pH}$ e teor foliar de $\mathrm{Ni}$ (Figura 3h), muito embora essa relação não fosse esperada e esteja limitada em função da pequena variaçáo no valor de $\mathrm{pH}$ observado nesse solo $(4-4,8)$. Alterando o $\mathrm{pH}$ de diferentes tipos de solo para valores entre 3 e 7,5, MelLis et al. (2004) relataram um aumento na adsorção de $\mathrm{Ni}$ no solo com o aumento do $\mathrm{pH}$, o que leva a uma reduçáo na disponibilidade deste elemento. Entretanto, os mesmos autores

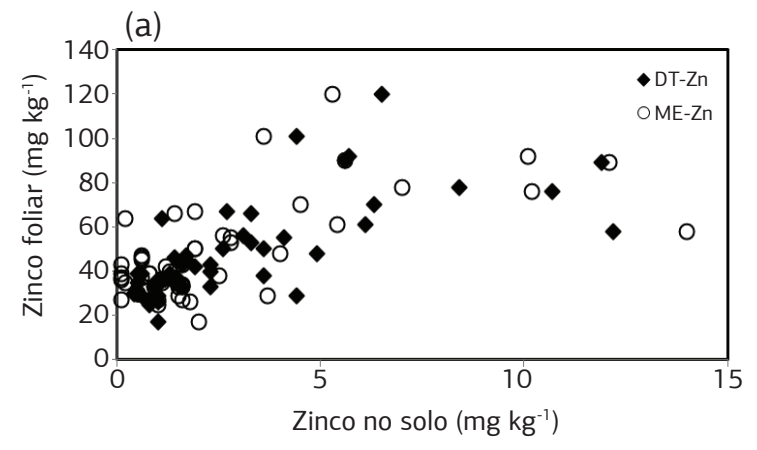

(b)

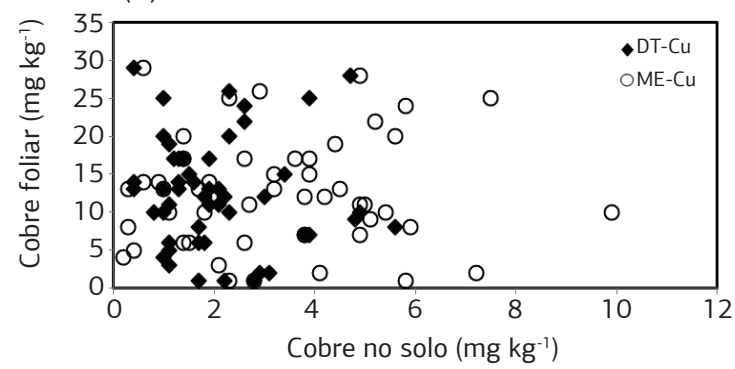

(c)

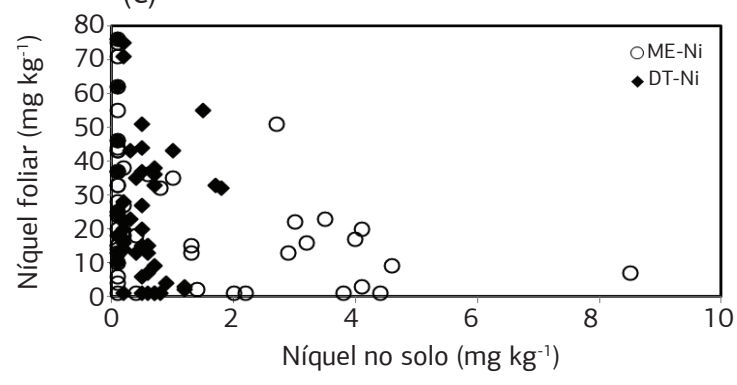

Figura 2. Correlação entre os teores foliares de zinco, cobre e níquel em Braquiária e os respectivos teores no solo, na camada de 0-20 cm de profundidade, determinados pelos extratores DTPA pH 7,3 (DT-Cu, DT-Zn, DT-Ni) e Mehlich-3 (ME-Cu, ME-Zn, $\mathrm{ME}-\mathrm{Ni}$ ).

Tabela 5. Análise estatística descritiva para os teores de matéria orgânica do solo (MOS), pH e capacidade de troca catiônica (CTC) na camada de $0-20 \mathrm{~cm}$ de profundidade em solo que recebeu lodo de esgoto

\begin{tabular}{|c|c|c|c|c|c|c|c|c|}
\hline \multirow{2}{*}{ Variável } & Média & DP & CV & Min. & Máx. & $C_{s k}$ & $C_{k}$ & \multirow{2}{*}{$\begin{array}{l}\text { K-S } \\
\mathrm{Pr}>000\end{array}$} \\
\hline & & & (\%) & & & & & \\
\hline $\operatorname{MOS}\left(\mathrm{g} \mathrm{kg}^{-1}\right)$ & 27,67 & 4,60 & 16,63 & 17,00 & 41,00 & 0,40 & 0,52 & 0,039 \\
\hline $\mathrm{pH}\left(\mathrm{CaCl}_{2}\right)$ & 4,17 & 0,18 & 4,48 & 3,90 & 4,80 & 1,13 & 1,53 & $<0,010$ \\
\hline CTC $\left(\mathrm{mmol}_{\mathrm{c}} \mathrm{dm}^{-3}\right)$ & 97,72 & 14,65 & 14,99 & 68,80 & 137,20 & 0,89 & 0,52 & $<0,010$ \\
\hline
\end{tabular}

DP: desvio-padrão; CV: coeficiente de variaçăo, Mín.: valor mínimo; Máx.: valor máximo; $\mathrm{C}_{\mathrm{sk}}$ : coeficiente de assimetria; $\mathrm{C}_{\mathrm{k}}$ : coeficiente de curtose; $\mathrm{K}-\mathrm{S}$ : teste de Kolmogorov-Sminov.

Tabela 6. Análise estatística descritiva para os teores de Zn, Cu e Ni nas folhas de braquiária cultivada em solo que recebeu lodo de esgoto

\begin{tabular}{|c|c|c|c|c|c|c|c|c|c|}
\hline \multirow{2}{*}{ Variável $\left(\mathrm{mg} \mathrm{kg}^{-1}\right)$} & Média & Mediana & DP & CV & Min. & Máx. & $\mathrm{C}_{\mathrm{sk}}$ & $C_{k}$ & \multirow{2}{*}{$\begin{array}{l}\text { K-S } \\
\text { Pr>0,05 }\end{array}$} \\
\hline & & & & (\%) & & & & & \\
\hline $\mathrm{Cu}$ & 12,56 & 12,00 & 7,28 & 57,96 & 1,00 & 29,00 & 0,43 & $-0,32$ & $>0,150$ \\
\hline $\mathrm{Zn}$ & 48,46 & 41,50 & 22,03 & 45,46 & 17,00 & 120,00 & 1,32 & 1,51 & $<0,010$ \\
\hline $\mathrm{Ni}$ & 25,00 & 20,00 & 20,06 & 80,24 & 1,00 & 76,00 & 0,90 & 0,29 & 0,079 \\
\hline
\end{tabular}

DP: desvio-padrăo; CV: coeficiente de variaçăo; Mín.: valor mínimo; Máx: valor máximo; $\mathrm{C}_{\mathrm{sk}}$ : coeficiente de assimetria; $\mathrm{C}_{\mathrm{k}}$ : coeficiente de curtose: K-S: teste de Kolmogorov-Smirnov. 
(a)

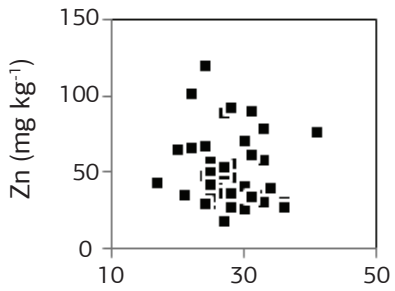

(d)

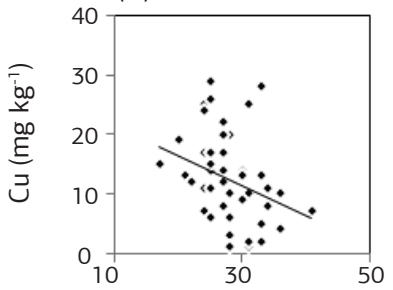

(g)

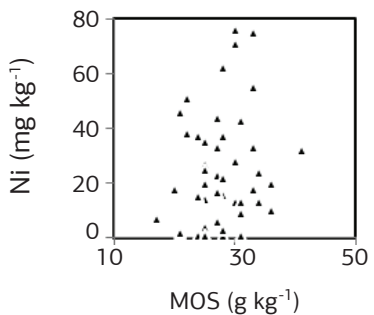

(b)

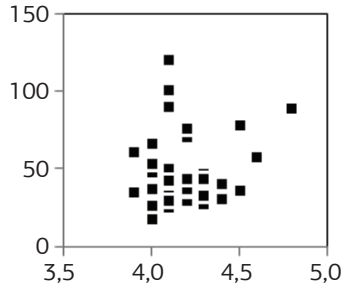

(e)

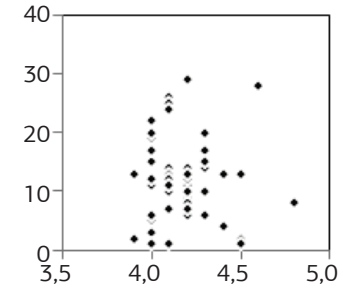

(h)

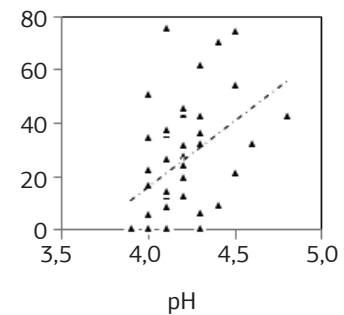

(c)

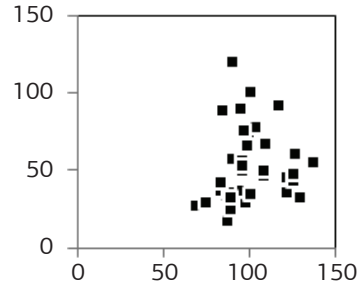

(f)

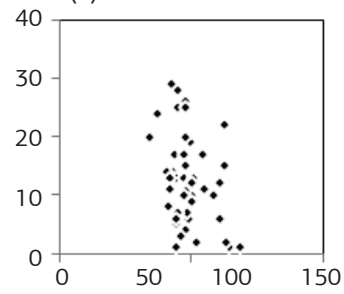

(i)

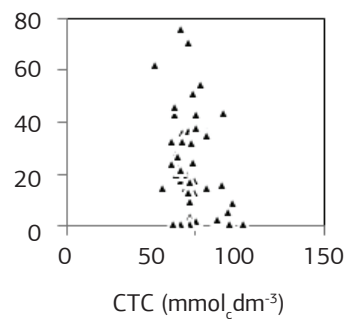

Figura 3. Correlação entre matéria orgânica do solo (MOS), pH, capacidade de troca catiônica (CTC) da camada de 0-20 cm de profundidade e teores foliares de $\mathrm{Cu}, \mathrm{Zn}$ e $\mathrm{Ni}$ em solo tratado com lodo de esgoto.

Tabela 7. Parâmetros de ajuste do semivariograma para os teores de $\mathrm{Zn}, \mathrm{Cu}$ e Ni extraídos com DTPA pH 7,3, em duas profundidades de um solo que recebeu lodo de esgoto

\begin{tabular}{|c|c|c|c|c|c|c|}
\hline \multirow{2}{*}{\multicolumn{2}{|c|}{ Variável }} & $C_{0}$ & $C_{1}$ & GDE & $\mathbf{a}$ & \multirow{2}{*}{ Modelo } \\
\hline & & \multicolumn{2}{|c|}{$\left(\mathrm{mg} \mathrm{kg}^{-1}\right)^{2}$} & $\%$ & m & \\
\hline \multirow{3}{*}{$0-20 \mathrm{~cm}$} & $\mathrm{Cu}$ & 0,17 & 0,62 & 21,50 & 14,00 & Esférico \\
\hline & $\mathrm{Zn}$ & 0,20 & 0,80 & 20,00 & 9,00 & Gaussiano \\
\hline & $\mathrm{Ni}$ & 0,63 & 0,35 & 64,29 & 8,00 & Esférico \\
\hline \multirow{3}{*}{$20-40 \mathrm{~cm}$} & $\mathrm{Cu}$ & 0,28 & 0,71 & 28,28 & 17,00 & Esférico \\
\hline & $\mathrm{Zn}$ & \multicolumn{5}{|c|}{ Efeito pepita puro } \\
\hline & $\mathrm{Ni}$ & 0,56 & 0,50 & 52,83 & 15,70 & Esférico \\
\hline
\end{tabular}

$\mathrm{C}_{0}$ : efeito pepita; $\mathrm{C}_{1}$ : patamar; GDE: grau de dependência espacial $\left(\mathrm{C}_{0} /\left(\mathrm{C}_{0}+\mathrm{C}_{1}\right) \mathrm{x}\right.$ 100); a: alcance do modelo.

também relataram que um aumento de $\mathrm{pH}$ de 4,1 para 4,6 resultou em um incremento na adsorção de $\mathrm{Ni}$, variável entre os solos, de apenas 1 a $12 \%$.

Em relação à variabilidade espacial dos metais pesados após quinze anos da última aplicação de LE, apenas para o teor de zinco determinado pelo DTPA pH 7,3, e na camada de $20-40 \mathrm{~cm}$ de profundidade, não foi possível estabelecer um modelo de dependência espacial definido pelo semivariograma. Para todos os demais elementos e
Tabela 8. Parâmetros de ajuste do semivariograma para os teores de $\mathrm{Zn}$, Cu e Ni extraídos com solução de Mehlich-3 em duas profundidades de um solo que recebeu lodo de esgoto

\begin{tabular}{|c|c|c|c|c|c|c|}
\hline \multirow{2}{*}{\multicolumn{2}{|c|}{ Variável }} & $C_{0}$ & $C_{1}$ & GDE & $\mathbf{a}$ & \multirow{2}{*}{ Modelo } \\
\hline & & \multicolumn{2}{|c|}{$\left(\mathrm{mg} \mathrm{kg}^{-1}\right)^{2}$} & $\%$ & m & \\
\hline \multirow{3}{*}{$0-20 \mathrm{~cm}$} & $\mathrm{Cu}$ & 0,12 & 0,95 & 11,21 & 25,00 & Esférico \\
\hline & $\mathrm{Zn}$ & 0,22 & 0,82 & 21,15 & 9,00 & Esférico \\
\hline & $\mathrm{Ni}$ & 0,37 & 0,65 & 36,37 & 19,00 & Esférico \\
\hline \multirow{3}{*}{$20-40 \mathrm{~cm}$} & $\mathrm{Cu}$ & 0,66 & 0,44 & 60,00 & 23,00 & Gaussiano \\
\hline & $\mathrm{Zn}$ & 0,04 & 0,98 & 3,92 & 11,00 & Esférico \\
\hline & $\mathrm{Ni}$ & 0,25 & 0,84 & 22,93 & 13,00 & Esférico \\
\hline
\end{tabular}

$\mathrm{C}_{0}$ : efeito pepita; $\mathrm{C}_{1}$ : patamar; GDE: grau de dependência espacial $\left(\mathrm{C}_{0} /\left(\mathrm{C}_{0}+\mathrm{C}_{1}\right) \times 100\right)$; a: alcance do modelo.

profundidades analisadas, os modelos esférico e gaussiano puderam descrever a dependência espacial observada para esses elementos no solo (Tabelas 7 e 8).

Em relação ao conteúdo foliar de $\mathrm{Cu}, \mathrm{Zn}$ e $\mathrm{Ni}$, no capim braquiária, foi possível estimar um modelo espacial para zinco e níquel, muito embora o grau de dependência espacial calculado tenha sido moderado $(\mathrm{Ni})$ e baixo $(\mathrm{Zn})$, e com valores de alcance da dependência espacial ao redor de $20 \mathrm{~m}$ (Tabela 9). 
Utilizando os modelos espaciais estimados para os teores dos elementos no solo, avaliados pelos dois extratores (Figura 4), e na planta (Figura 5), foram interpolados mapas por krigagem ordinária. Tendo em vista que os teores de $\mathrm{Cu}$ e $\mathrm{Zn}$ no solo tiveram dependência espacial

Tabela 9. Parâmetros de ajuste do semivariograma para as concentraçóes de Zn, Cu e Ni nas folhas de braquiária cultivada em solo que recebeu lodo de esgoto

\begin{tabular}{|c|c|c|c|c|c|}
\hline \multirow{2}{*}{$\begin{array}{l}\text { Variável } \\
\left(\mathrm{mg} \mathrm{kg}^{-1}\right)^{2}\end{array}$} & $C_{0}$ & $C_{1}$ & GDE & $\mathbf{a}$ & Modelo \\
\hline & & & $\%$ & m & \\
\hline $\mathrm{Cu}$ & \multicolumn{5}{|c|}{ Efeito pepita puro } \\
\hline $\mathrm{Zn}$ & 0,74 & 0,20 & 78,72 & 19,00 & Gaussiano \\
\hline $\mathrm{Ni}$ & 0,62 & 0,44 & 58,49 & 21,00 & Gaussiano \\
\hline
\end{tabular}

$\mathrm{C}_{0}$ : efeito pepita; $\mathrm{C}_{1}$ : patamar; GDE: grau de dependência espacial $\left(\mathrm{C}_{0} /\left(\mathrm{C}_{0}+\mathrm{C}_{1}\right) \times 100\right)$; a: alcance do modelo.
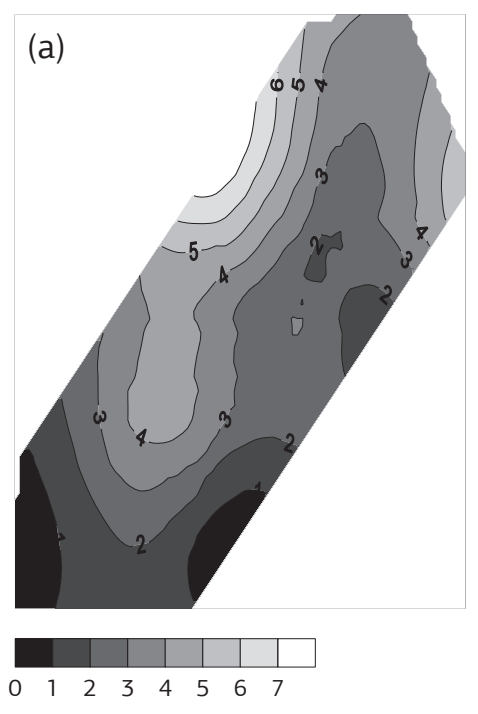

Cobre
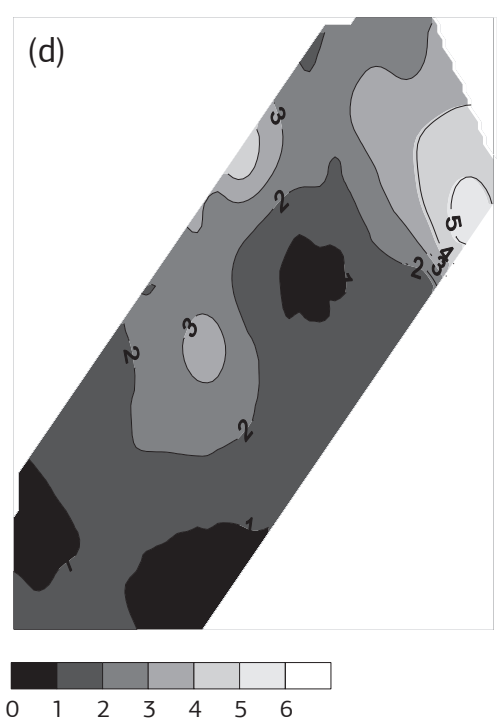

Cobre

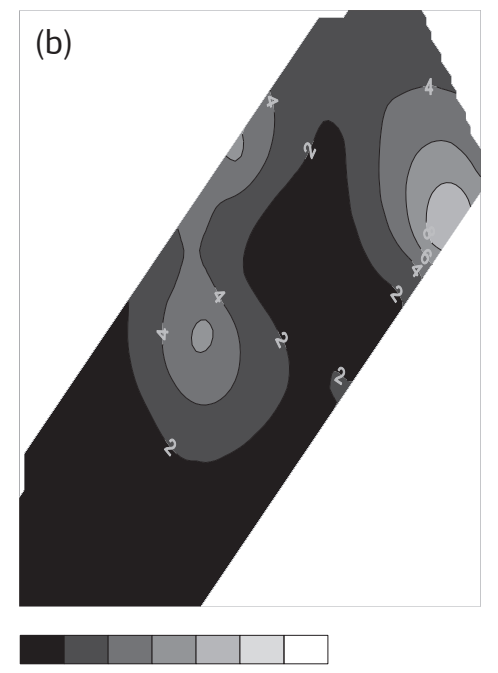

$\begin{array}{llllllll}0 & 2 & 4 & 6 & 8 & 10 & 12\end{array}$

Zinco

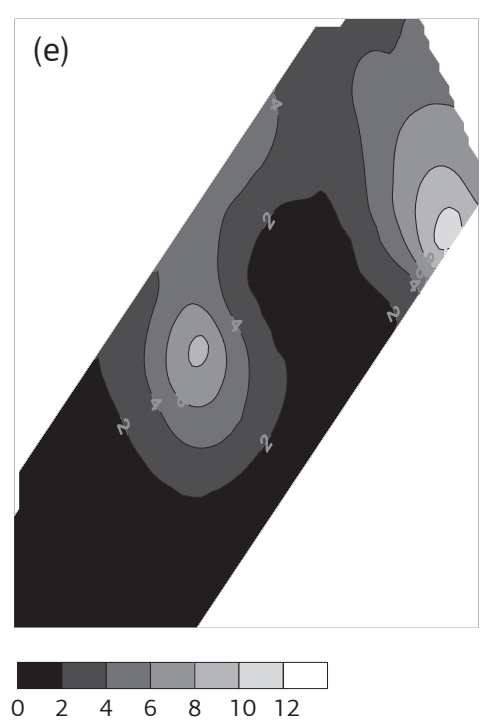

Zinco classificada como forte, com GDE até 25\% apenas na camada de 0-20 cm de profundidade, esta camada foi usada para a interpolação dos mapas (Figura 4). As variações nos teores de $\mathrm{Cu}\left(0-7 \mathrm{mg} / \mathrm{dm}^{3}\right)$ e de $\mathrm{Zn}\left(0-12 \mathrm{mg} / \mathrm{dm}^{3}\right)$ no solo detectadas tanto pelo DTPA (Figura 4a,b) quanto pelo Mehlich-3 (Figura 4d,e), tiveram certa correspondência com os teores foliares desses mesmos elementos (Figura 5). Principalmente para o $\mathrm{Zn}$, este resultado chama a atenção devido à correlação entre os teores foliares e os disponíveis no solo (Figura 2a).

Para o $\mathrm{Ni}$, variaçóes de quase dez vezes os teores encontrados entre os dois extratores não permitem uma generalização acerca da correspondência de manchas de solo e teores foliares, mas segundo o mapa interpolado (Figura 5) é nítida a presença de manchas com teores diferenciais do elemento na área estudada.

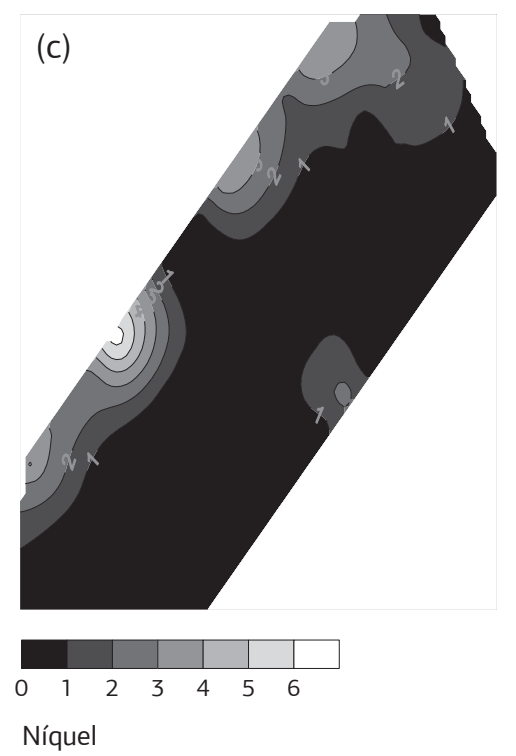

Figura 4. Distribuição espacial de $\mathrm{Cu}(\mathrm{a}, \mathrm{d}), \mathrm{Zn}(\mathrm{b}, \mathrm{e})$ e Ni (c,f) na camada de 0-20 cm de solo tratado com lodo de esgoto e avaliados pelos extratores DTPA pH 7,3 (a-c) e Mehlich-3 (d-f). 

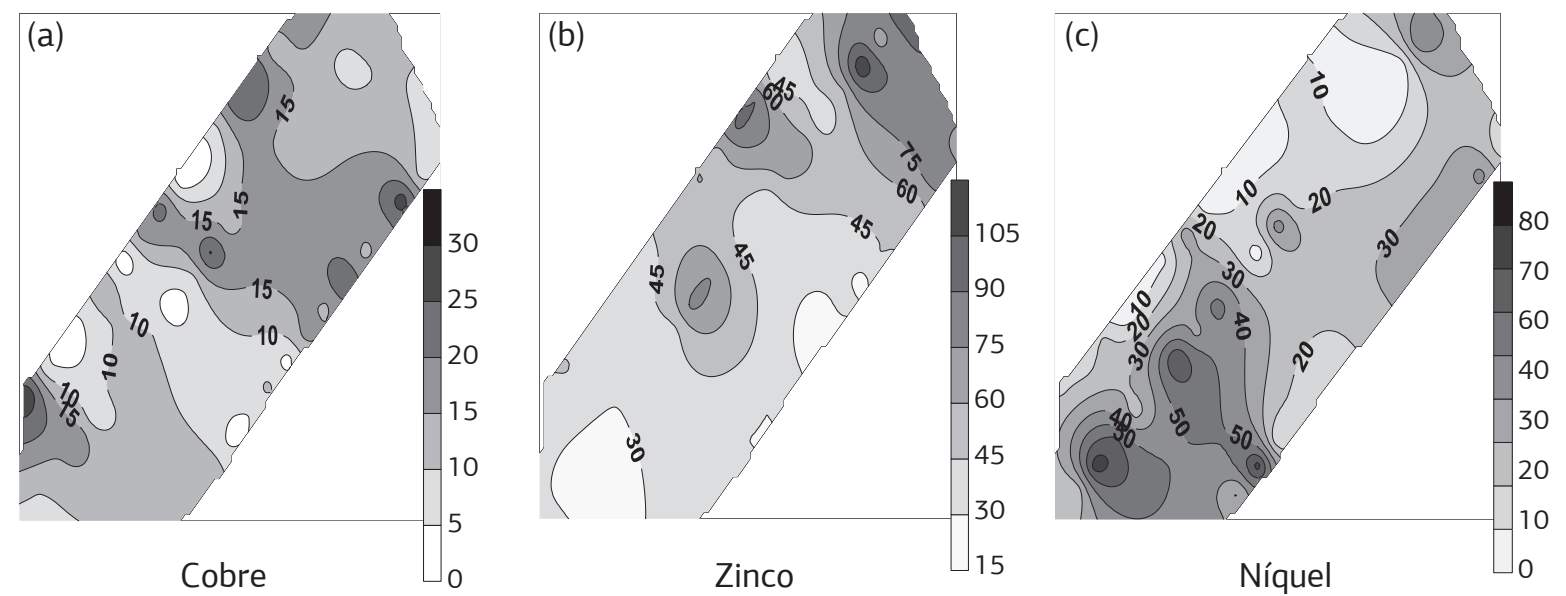

Figura 5. Mapas dos teores foliares de $\mathrm{Cu}$ (a), Zn (b) e $\mathrm{Ni}$ (c) em braquiária cultivada em solo tratado com lodo de esgoto. Valores calculados por krigagem ordinária. Notar as diferenças nas escalas.

\section{DISCUSSÃO}

Os diferentes tratamentos resultaram em um gradiente de $\mathrm{Cu}, \mathrm{Zn}$ e Ni aportados no solo que variam de $16-78 \mathrm{~kg} \mathrm{ha}^{-1}$ de Cu, 38-194 $\mathrm{kg} \mathrm{ha}^{-1}$ de Zn e 7-48 kg ha ${ }^{-1}$ de Ni (Tabela 2). $\mathrm{O}$ aporte das quantidades desses metais, bastante acima das necessidades da espécie vegetal estudada no que concerne à sua utilização como nutriente de plantas, justifica o interesse em se conhecer sua variabilidade espacial no sistema solo-planta, tendo em vista que esses elementos podem permanecer no solo por longo tempo (McGrath, 1984). Este estudo também se justifica ao se levar em consideração que metais adicionados por aplicação de LE, tendem a permanecer na zona de incorporação do resíduo no solo $(0-20 \mathrm{~cm})$ como resultado da sua interação com óxidos, minerais de argila e matéria orgânica (Alloway e JACKSON, 1991).

Os altos valores dos coeficientes de variaçáo para os teores de $\mathrm{Cu}, \mathrm{Zn}$ e $\mathrm{Ni}$ no solo estão de acordo com as diferentes quantidades aportadas desses elementos. Adicionalmente, seria pertinente destacar que o longo período em que a área permaneceu sob pousio resultou em $\mathrm{pH}$ baixo, fato que pode ter favorecido a disponibilidade desses metais tendo em vista uma ciclagem mais rápida entre o solo e a planta. Esse fato também poderia explicar, em parte, o aumento da heterogeneidade em funçáo da deposição diferencial de biomassa na área.

Os teores foliares desses elementos tiveram grande variação que pode ser reflexo tanto das correspondentes manchas no solo em funçáo dos tratamentos com biossólido quanto devido a características da própria planta. Elevados coeficientes de variação para os teores de Cu e Zn em plantas de braquiária podem ser uma característica intrínseca desta cultura, tendo em vista que Silveira et al. (2005) observaram coeficientes de variaçáo de $106 \%$ a $51 \%$, respectivamente, para $\mathrm{Cu}$ e $\mathrm{Zn}$, cultivando as plantas em solução nutritiva. As plantas, todavia, seriam indicadoras adequadas da biodisponibilidade desses elementos no sistema (CHen et al., 2010) e nos mapas obtidos (Figura 5). Verifica-se que, mesmo 15 anos após a última aplicação de LE, os teores foliares desses elementos possuem dependência espacial definida e passível de ser descrita por um modelo semivariográfico e mapeada por krigagem.

Tendo em vista que os teores de $\mathrm{Zn}$ extraídos do solo, tanto pelo DTPA quanto pelo Mehlich-3 correlacionaram-se significativamente com os teores na planta, que a única fonte de $\mathrm{Zn}$ utilizada foi o LE e considerando que a biomassa produzida náo foi retirada da área, seria razoável analisar se as alteraçôes ocasionadas pelo aporte desses metais ainda estariam sendo detectadas no momento da amostragem de solo e planta. Neste contexto, infere-se que o uso da análise geoestatística e o mapeamento dos teores de $\mathrm{Zn}$ podem ser considerados ferramentas úteis para avaliar o impacto da aplicação do LE em longo prazo.

Pela análise dos parâmetros de ajuste dos semivariogramas, observa-se que o grau de dependência espacial dos teores de $\mathrm{Cu}, \mathrm{Zn}$ e Ni nas plantas foi diferente do verificado para o solo. De acordo com Chen et al. (2010), apesar de os teores presentes nos tecidos vegetais terem, geralmente, correlação significativa com os teores disponíveis no solo por diversos extratores, esses elementos têm comportamentos distintos no solo devido a uma série de processos físico-químicos que controlam sua disponibilidade aos vegetais, tal como as formas químicas nas quais estâo contidos. Desta forma, estudos relacionados com a distribuição espacial desses elementos no sistema solo-planta deveriam investigar além dos teores tidos como disponíveis e avaliados por extratores químicos, suas diferentes formas e associaçóes no solo para entender sua correlação com a distribuição espacial dos teores nas plantas. Este fato pode 
ser nitidamente identificado quando são comparados os valores de alcance dos semivariogramas calculados para os diferentes elementos determinados por diferentes extratores. Destaca-se que teores de $\mathrm{Zn}$ extraídos por DTPA tenham tido correlação com teores foliares mesmo muitos anos após a suspensão da aplicação de LE. Em razão da natureza deste extrator (Sommers et al., 1991; Hooda e Alloway, 1994), estes resultados indicam a existência de teores de $\mathrm{Zn}$ associados a frações trocáveis (HAN et al., 2000) e que ainda exibem característica espacial passível de ser modelada e mapeada, contrariando a expectativa inicial de que não seria mais possível estabelecer um modelo de dependência espacial para estes dados.

\section{CONCLUSÃO}

Os atributos do solo $\mathrm{pH}, \mathrm{MOS}$ e CTC não estão correlacionados com os teores de $\mathrm{Cu}, \mathrm{Zn}$ e Ni nas plantas. Tanto o DTPA quanto o Mehlich-3 são eficientes na predição da disponibilidade de $\mathrm{Zn}$ no solo e na planta.

Após 15 anos da aplicação de biossólido, os teores de $\mathrm{Cu}, \mathrm{Zn}$ e Ni na camada de $0-20 \mathrm{~cm}$ de profundidade do solo e determinados tanto com DTPA quanto Mehlich-3 têm estrutura de dependência espacial classificada como forte e/ou moderada. O grau de dependência espacial dos teores de $\mathrm{Cu}, \mathrm{Zn}$ e Ni, nas plantas, é diferente do verificado para esses elementos no solo.

\section{REFERÊNCIAS}

ALLOWAY, B.J.; JACKSON, A.P. The behaviour of heavy metals in Sewage sludge amended soils. Science of Total Environment, v.100, p.151-176, 1991.

ANJOS, A.R.M; MATTIAZZO, M.E. Metais pesados em plantas de milho cultivadas em Latossolos repetidamente tratados com biossólido. Scientia Agricola, v.57, p.769-776, 2000.

ANJOS, A.R.M; MATTIAZZO, M.E. Extratores para Cd, Cu, $\mathrm{Cr}, \mathrm{Mn}, \mathrm{Ni}, \mathrm{Pb}$ e $\mathrm{Zn}$ em Latossolos tratados com biossólido e cultivados com milho. Scientia Agricola, v.58, p.337-344, 2001.

BERTON, R.S. Riscos de contaminação do agroecossistema com metais pesados. In: BETTIOL, W.; CAMARGO, O.A. (Ed.). Impacto ambiental do uso agrícola do lodo de esgoto. Jaguariúna: Embrapa Meio Ambiente, 2000. p.259-268.

BERTON, R.S.; CAMARGO, O.A.; VALADARES, J.M.A.S. Absorção de nutrientes pelo milho em resposta à adiçáo de lodo de esgoto a cinco solos paulistas. Revista Brasileira de Ciência do Solo, v.13, p.187-192, 1989.

BETTIOL, W.; CARVALHO, P.C.T. Lodo de esgoto como fertilizante para a cultura do milho (Zea mays L.) Hibrido Hmd7974. Fertilizantes, v.4, p.9-11, 1982.
BIDWELL, A.M.; DOWDY, R.H. Cadmuim and zinc availability to corn following termination of sewage sludge applications. Journal of Environmental Quality, v.16, p.438-442, 1987.

BORGES, M.R.; COUTINHO, E.L.M. Metais pesados do solo após aplicação de biossolido. II. Disponibilidade. Revista Brasileira de Ciência do Solo, v.28, p.557-568, 2004.

CAMARGO, O.A.; ALLEONI, L.R.F.; CASAGRANDE, J.C. Reaçóes dos micronutrientes e elementos tóxicos no solo. In: FERREIRA, M.E.; CRUZ, M.C.P.; RAIJ, B. van; ABREU, C.A. (Ed.). Micronutrientes e elementos tóxicos na agricultura. Jaboticabal: CNPq/FAPESP/POTAFOS, 2001. p.89-124.

CAMARGO, O.A.; MONIZ, A.C.; JORGE, J.A.; VALADARES, J.M.A.S. Métodos de análise química, mineralógica e física de solos. Campinas: Instituto Agronômico de Campinas, 1986. 94p. (Boletim Técnico, 106)

CAMBARDELLA, C.A.; MOORMAN, T.B.; NOVAK, J.M.; PARKIN, T.B.; KARLEN, D.K.; TURCO, R.F.; KONOPKA, A.E. Field-scale variability of soil properties in central Iowa soils. Soil Science Society of America Journal, v.58, p.1501-1511, 1994.

CHEN, C.Y.; ZHANG, P.Y.; ZENG, G.M.; DENG, J.H.; ZHOU, Y.; LU, H.F. Sewage sludge conditioning with coal fly ash modified by sulfuric acid. Chemical Engineering Journal, v.158, p.616-622, 2010.

DE MARIA, I.C.; CHIBA, M.K.; COSTA, A., BERTON, R.S. Sewages sludge application to agricultural and as soil physical conditioner. Revista Brasileira de Ciência do Solo, v.34, p.967-974, 2010 .

GALDOS, M.V.; DE MARIA, I.C.; CAMARGO, O.A. Atributos químicos e produção de milho em um Latossolo Vermelho eutroférrico tratado com lodo de esgoto. Revista Brasileira de Ciência do Solo, v.28, p.569-577, 2004.

GARDINER, D.T.; MILLER, R.W.; BADAMCHIAN, B.; AZZARI, A.S.; SISSON, D.R. Effects of repeated sewage sludge applications on plant accumulation of heavy metals. Agriculture, Ecosystems and Environment, v.55, p.1-6, 1995.

HAN, F.X.; KINGERY, W.L.; SELIM, H.M.; GERARD, P.D. Accumulation of Heavy Metals in A Long-Term Poultry WasteAmended Soil. Soil Science, v.165, p.260-268, 2000.

HOODA, P.S.; ALLOWAY, B.J. The plant availability and DTPA extractability of trace metals in sludge-amended soils. Science of Total Environment, v.149, p.39-51. 1994.

JORGE, J.A.; CAMARGO, O.A.; VALADARES, J.M.A.S. Condições físicas de um Latossolo Vermelho-Escuro quatro anos após aplicação de lodo de esgoto e calcário. Revista Brasileira de Ciência do Solo, v.15, p.237-240, 1991.

LINDSAY W.L.; NORVELL, W.A. Development of a DTPA soil test for zinc, iron, manganese, and copper. Soil Science Society of America Journal, v.42, p.421-428, 1978.

LOGAN, T.J.; LINDSAY, B.J.; GOINS, L.E.; RYAN, J.A. Field assessment of sludge metal bioavailabity to crops: sludge rate response. Journal of Environmental Quality, v.26, p.543-550, 1997. 
MALAVOLTA, E.; VITTI, G.C.; OLIVEIRA, S.A. Avaliação do estado nutricional das plantas: Princípios e aplicaçóes. 2.ed. Piracicaba: Associação Brasileira para Pesquisa da Potassa e do Fosfato, 1997.319p.

MARTINS, A.L.C.; BATAGLIA, O.C.; CAMARGO, O.A. Copper, nickel and zinc phytoavailability in an Oxisol amended with sewage sludge and liming. Scientia Agricola, v.60, p.747-754, 2003.

MCGRATH, S.P. Metal concentration in sludges and soil from a long term field trial. Journal of Agricultural Science, v.103, p.2535,1984

MEHLICH, A. Mehlich 3 soil test extractant: A modification of Mehlich 2 extractant. Communications in Soil Science and Plant Analysis, v.15, p.1409-1416. 1984.

MELLIS, E.V.; CRUZ, M.C.P.; CASAGRANDE, J.C. Nickel adsorption by soils in relation to $\mathrm{pH}$, organic matter and iron oxides. Scientia Agricola, v.61, p.190-195, 2004.

NOGUEIRA, T.A.; OLIVEIRA, L.R.; MELO, W.J.; FONSECA, I.M.; MELO, G.M.P.; MELO, V.P. MARQUES, M.O. Cádmio, cromo, chumbo e zinco em plantas de milho e em Latossolo após nove aplicaçóes anuais de lodo de esgoto. Revista Brasileira de Ciência do Solo, v.32, p.2195-2207, 2008.

OLIVEIRA, F.C.; MATTIAZZO, M.E. Metais pesados em Latossolo tratado com lodo de esgoto e em plantas de cana-deaçúcar. Scientia Agricola, v.58, p.581-593, 2001.

PIRES, A.M.; MATTIAZZO, M.E. Biosolids conditioning and availability of $\mathrm{Cu}$ and $\mathrm{Zn}$ for rice. Scientia Agricola, v.60, p.161166, 2003.

RAIJ, B. VAN; QUAGGIO, J.A.; CANTARELLA, H.; FERREIRA, M.E.; LOPES, A.S.; BATAGLIA, O.C. Análise química do solo para fins de fertilidade. Campinas: Fundação Cargill, 1987. 170p.

SHUMAN, L.M. Chemical forms of micronutrients in soils. In: MORTVEDT, J.J.; COX, F.R.; SHUMAN, L.M.; WELCH, R.M. (Ed.). Micronutrients in Agriculture. 2.ed. Madison: Soil Science Society of America, 1991. p.113-144.

SILVEIRA, C.P.; NACHTIGALL, G.R.; MONTEIRO, F.A. Testing and validation of methods for diagnosis and recommendation integrated for signal grass. Scientia Agricola, v.62, p. $520-527,2005$.

SILVEIRA, M.L.A.; ALLEONI, L.R.F.; GUILHERME, L.R.G. Biosolids and heavy metals in soils. Scientia Agricola, v.60, p.793806, 2003.

SOMMERS, L.E.; PAGE, A.L.; LOGAN, T.J.; RYAN, J.A. Impact of sewage sludge on soils and barley: a regional study. Optimum use of sewage sludge on agricultural land. Fort Collins: Agricultural Experimental Station at Colorado State University, 1991. (Western Regional Research Publication W-124)

TRANNIN, I.C.B.; SIQUEIRA, J.O.; MOREIRA, F.M.S. Atributos químicos e físicos de um solo tratado com biossólido industrial e cultivado com milho. Revista Brasileira de Engenharia Agrícola e Ambiental, v.12, p.223-230, 2008.

VIEIRA, S.R. Geoestatistica em estudos de variabilidade espacial do solo. In: NOVAIS, R.F.; ALVAREZ, V.H.; SCHERER, C.E.G.R. (Ed.). Tópicos em Ciência do Solo. Viçosa: Sociedade Brasileira de Ciência do Solo, 2000. v.1. p.1-54.

WALTER, I.; MARTINEZ, F.; ALONSO, L.; GRACIA, J.; CUEVAS, G. Extractable soil heavy metals following the cessation of biosolids application to agricultural soil. Environmental Pollution, v.117, p.315-321, 2002. 